\title{
Transparency in Supply Chains (TISC): Assessing and Improving the Quality of Modern Slavery Statements
}

\author{
Bruce Pinnington $^{1}$ (1) . Amy Benstead ${ }^{2} \cdot$ Joanne Meehan $^{1}$
}

Received: 5 July 2021 / Accepted: 7 January 2022 / Published online: 21 January 2022

(c) The Author(s) 2022

\begin{abstract}
Transparency lies at the heart of most modern slavery reporting legislation, but while publication of statements is mandatory, conformance with content guidance is voluntary, such that overall, corporate responses have been poor. Existing studies, concentrated in business to consumer rather than inter-organisational contexts, have not undertaken the fine-grained assessments of statements needed to identify which aspects of reporting performance are particularly poor and the underlying reasons that need to be addressed by policy makers. In a novel design, this study utilises the ethical trade initiative assessment framework to evaluate the content of 95 UK government suppliers' modern slavery statements. The findings suggest that in a modern slavery context, discovery challenges are more important than firms' attitudes to disclosure. We contribute to the transparency literature through a model contrasting discovery costs and disclosure risks and by identifying the disclosure of unknowns as an additional relevant dimension of disclosure. We then discuss the model in relation to normativity theory to consider options through which the currently low legitimacy of the reporting governance regime can be enhanced and the intended norms established.
\end{abstract}

Keywords Transparency in supply chains $\cdot$ Modern slavery $\cdot$ Supply chain disclosure $\cdot$ Normativity

\section{Introduction}

Modern slavery in its various guises is an abhorrent, global, contemporary phenomenon. The International Labour Organisation estimates that 25 million people worldwide are trapped in some form of forced labour (ILO, 2019). An estimated $60 \%$ are in the Asia-Pacific region, according the Walk Free Foundation's Global Slavery Index (WFF, 2018), but with estimates for western nations also reaching six figures, businesses can be implicated in modern slavery through intranational and international supply chains. Fundamentally, modern slavery is a commercial phenomenon,

Bruce Pinnington

b.pinnington@liverpool.ac.uk

Amy Benstead

amy.benstead@manchester.ac.uk

Joanne Meehan

jomeehan@liverpool.ac.uk

1 Management School, University of Liverpool, Chatham Street, Liverpool L69 7ZH, UK

2 Department of Materials, University of Manchester, Oxford Road, Manchester M13 9PL, UK in which people are exploited for financial gain through practices of permanent enslavement, debt bondage, and contract slavery where people are tied through deceptive or exploitative contracts (Gold et al., 2015). Eradication of modern slavery is politically challenging (New, 2020), and in recognition of its commercial underpinning, legislators internationally have sought to influence businesses by requiring in-scope firms to report on modern slavery risks in their supply chains, and on actions they have taken to address those risks (Christ et al., 2019).

Transparency and reporting are at the heart of most modern slavery legislation, such as the Californian Transparency in Supply Chains (TISC) Act 2010, Section 54 of the UK modern slavery act (MSA) 2015, and the Australian MSA, 2018. These examples differ in their statutory requirements, but even with the Australian MSA, which goes as far as identifying statutory reporting criteria, the content of reports is otherwise voluntary. Reporting guidance for firms is published for the Californian Act (Harris, 2015), the UK MSA (HMG, 2018), and the Australian MSA (AuGov, 2018), but as firms do not have to follow guidance there is little effective control over statement content. In other jurisdictions, such as France and 
Brazil, transparency is also fundamental to the policy approach. In France, the Corporate Duty of Vigilance, 2017 law, requires firms to produce a vigilance plan to identify and manage risks relating to human rights and freedoms (Christ et al., 2019), including those relating to established supply chain relationships (Cossart et al., 2017). In Brazil, a name-and-shame register was created to identify firms linked with slavery, but there, the approach has been undermined by suspension (Feasley, 2015), legal challenges, and restructuring of government departments.

Transparency is considered to be fundamental to driving ethics-oriented behavioural changes in supply chain management practices (Doorey, 2011), through a process in which corporate concerns for potential reputational damage motivates action (Gold \& Heikkurinen, 2018; Monciardini et al., 2021; Rogerson et al., 2020). However, doubts have been expressed about the effectiveness of transparency policies in achieving disclosure of non-financial information generally (Hess, 2019), and for modern slavery reports specifically (LeBaron \& Rühmkorf, 2017; Monciardini et al., 2021). Responses to the Californian TISC act, for instance, have been symbolic rather than substantive (Birkey et al., 2018) and NGOs consider responses to the UK MSA to be weak and disappointing (Monciardini et al., 2021).

The problem currently, is that little has been established about the quality of transparency reports, especially in relation to modern slavery. Academic studies, to date, have concentrated on legal compliance and exploration of themes covered by statements (e.g. Flynn \& Walker, 2021; Stevenson \& Cole, 2018; Voss et al., 2019) rather than undertaking detailed analyses of how well statements match government guidance. In a context where legislation is light-touch, statutory compliance is easily achieved irrespective of the quality of the report.

Reporting quality is important because, currently, statements constitute the best available proxy for supply chain action (Hess, 2019). Although local reporting mechanisms, such as the National Referral Mechanism in the UK, can put firms with poor national practices in the spotlight, the complexities of international supply chains, and the hidden nature of modern slavery, compromise visibility unless firms are prepared actively to investigate, report and manage risks of labour abuse. However, little is known about the relative strengths and weaknesses of the different reporting elements comprising statements, such that policy makers are short of meaningful guidance on where the real challenges lie. Consequentially, there is an urgent need for a dependable method for assessing and grading statement quality, which provides detailed insights into transparency practices that may then be interpreted against policy options. Legislation is not the only option available. Governments can exert influence on industry through additional best practice guidance, through leadership, and through their own buying power.
Governments have exhibited a strong preference for reporting and transparency strategies, (Christ et al., 2019) rather than more extensive legislation that is potentially complex and expensive to administer. Anticipated US and EU modern slavery legislation has been subject to extensive delay, the French Corporate Duty of Vigilance law had envisaged penalties watered down (Feasley, 2015) and UK Government response (HMG, 2019b) to an independent parliamentary review of the MSA (Field et al., 2019) indicates a reluctance to pursue extensive legislation as its primary strategy, so it is important that other sources of influence are also considered. In the UK context, the government is attempting to influence practice with further guidance in the form of the Home Office's modern slavery assessment tool (MSAT) (HMG, 2019a) and through its cooperation with non-government organisations such as the ethical trading initiative (ETI). Secondly, leadership is demonstrated by the Government's voluntary publication of its own modern slavery statement (HMG, 2020). Thirdly, with spend of $£ 255 \mathrm{Bn}$, the UK Government is in a strong position to influence its supply chain. Public procurement is an under-utilised tool in effecting human rights change (Martin-Ortega, 2018), but the UK Government recognises this potential and has recently issued internal guidance setting out how modern slavery should be evaluated in tender responses, and managed operationally thereafter (Government Commercial Function, 2019).

Accordingly, it is important that policy makers and practitioners understand the relative strengths and weaknesses of corporate responses to modern slavery legislation such that they can evaluate the utility of both coercive and non-coercive power sources in improving corporate responses. Our research therefore considers the questions: to what extent do corporate responses to the UK MSA indicate that policy ambitions are being met, and what are the implications for policy makers and practitioners?

The UK provides an ideal context in which to study modern slavery reporting because of its unique combination of: a statutory annual reporting cycle; detailed guidance (HMG, 2018); inclusion of both services and products, and long enough established legislation such that all in-scope firms should have developed reporting practices through several reporting cycles. ETI's modern slavery statement assessment framework (ETI, 2019) enables fine-grained analysis of statement quality, and is utilised in this study to assess the content of 95 UK central government suppliers' statements. Studies to date, concentrate on business to consumer (B2C) contexts where transparency logic expects that consumer pressure will exert maximum influence on firms' reporting inclination. Business-to-business (B2B) and businessto-government (B2G) contexts have been largely ignored, but typically feature long-term relationships and formal contracting processes through which client organisations 
can exert significant influence on reporting standards. The B2G context in this study provides an opportunity to study this important category of firms and to consider how the Government's different influencing options may impact performance.

The findings indicate that despite these additional levers, most statements sit at or below a basic performance standard (level 1 in the 3-level ETI framework), signifying that established reporting norms are decoupled from social expectations (Huq \& Stevenson, 2020). Firms' appetite for information discovery may be a more important factor than disclosure strategy in achieving policy objectives and public policy therefore needs to address firms discovery costs and disclosure risks. We contribute to transparency literature through a model contrasting discovery costs and disclosure risks and by highlighting the importance of disclosure of unknowns. We draw on normativity theory to consider routes through which transparency may be enhanced, and the legitimacy of the reporting governance regime, established.

\section{Literature Review}

Increasingly, firms are held responsible for the performance of their suppliers (Swift et al., 2019), so firms need to ensure that social responsibilities are managed through the multiple tiers of their supply chains (Grimm et al., 2016; Soundararajan \& Brammer, 2018; Wilhelm et al., 2016a, 2016b). However, it can be challenging for firms to identify modern slavery, even with direct suppliers (Swift et al., 2019), so the risks of labour exploitation and human rights in multi-tier, distributed supplier networks, featuring extensive sourcing from developing countries, are considerably compounded (LeBaron \& Rühmkorf, 2017). This complexity also presents difficult challenges to policy makers (Koekkoek et al., 2017). In the following sections, studies of modern slavery in supply chains are reviewed in the context of the transparencybased governance regimes through which policy makers seek to influence reporting practices. The concept of reporting normativity is also introduced, as a basis for evaluating the effectiveness of governance regimes in establishing their intended standards of reporting norms.

\section{Modern Slavery Legislation and Voluntary Reporting}

In recognition of the difficulties in enforcing stringent regulation, legislators instead have preferred to table transparency legislation, based on cooperation and voluntary reporting. The UK MSA 2015 and Australian MSA 2018, in common with the earlier Californian TISC Act 2010, are founded on the premise that transparency will enable increased stakeholder scrutiny that drives firms to address modern slavery risks (Birkey et al., 2018). Transparency policy is typically based on the twin logics of trickle-down influence and reputational pressure. The (unsubstantiated) logic of trickle-down influence, argues that improvements in large firms' practices will be passed on to small firms (Rogerson et al., 2020) through a combination of contractual requirements and supplier development practices (Grimm et al., 2018; Wilhelm et al., 2016a). The logic of reputational pressure is predicated on the belief that through greater transparency, consumers will become more sensitised to modern slavery and will pressure firms into more impactful action (Barna, 2017).

Transparency legislation improves awareness of upstream risks amongst stakeholders, such as customers, media and non-governmental organisations (NGOs) (LeBaron \& Rühmkorf, 2017; New, 2015), but typically statutory obligations are limited to only a few basic publication-oriented requirements, with non-binding guidance (AuGov, 2018; Harris, 2015; HMG, 2018) used to establish the reporting standards sought by policy makers. In practice, this affords firms considerable reporting freedom such that wide variations are noted in information disclosed in response to the Californian act (Koekkoek et al., 2017) and the UK act (Stevenson \& Cole, 2018). The outcome is a disappointing response from firms (Monciardini et al., 2021) with suggestions that the transparency ideal has not yet lived up to expectations (Koekkoek et al., 2017). The Californian TISC act, is considered to have serious shortcomings with lax and unenforceable requirements (Gutierrez, 2017). The UK MSA, considered ground-breaking by a parliamentary report (Field et al., 2019), is similarly criticised for its light-touch approach (Flynn \& Walker, 2021; LeBaron \& Rühmkorf, 2019).

Gold and Heikkurinen (2018) draw attention to the transparency fallacy, to emphasise that transparency may not lead to accountability and responsible behaviour. They refer to "responsibility narratives" that can either omit or exaggerate activities. Voluntary reporting may also be ineffective in a modern slavery context because of its complex and distinctive characteristics (New, 2015), and the reporting freedom may also deflect attention from labour laws as the principal remedy to modern slavery (Fudge, 2018). There is therefore a risk that governments enter a "transparency trap" where they are attracted to an option with low implementation costs, but one which does not further their stated goals because firms' disclosure goals are image oriented, rather than outcome oriented (Hess, 2019).

\section{Transparency and Disclosure}

Tensions emerge between transparency policy and practice, because whilst implementation costs of transparency policies to government are relatively low, firms face significant 
costs in mapping supply chains and discovering relevant information (Doorey, 2011), and disclosure risks need to be carefully weighed against benefits, as well as competitors' strategies (Chen \& Slotnick, 2015). Firms typically adopt one of four disclosure strategies: transparency, where data are fully and openly disclosed; secrecy, where supply chain information is withheld for commercial reasons; distraction, where over-reporting of information is used to disguise a lack of meaningful content, or finally withholding, where firms neither seek, nor report information (Marshall et al., 2016). Disclosure options, however, depend on effective information discovery, and conventional corporate social responsibility (CSR) discovery practices may not be appropriate in a modern slavery context, where the issue is less tangible and often hidden (New, 2015).

Processes need to encompass product and labour supply chains for domestic and global supply chains (Crane et al., 2019). Supply chain audits are a common approach for transparency, but can be resource intensive and require close collaboration to be effective (Benstead et al., 2021). Although the costs and risks may negatively influence firms' transparency decisions, those that have embraced a transparency strategy, such as Nike, have seen their reputation enhanced (Marshall et al., 2016) and consequently have extended their commitment to transparency (Chen et al., 2019). Similarly, costs may be mitigated through discovery processes, such as audits, that generate other benefits through improved buying practices, supply chain streamlining and more efficient inventory management (Swift et al., 2019). Ultimately, as pressure from ethical NGOs grows (Benstead et al., 2021), firms have to consider that if they fail to adopt an open disclosure strategy, others may do it for them (New, 2010).

\section{Reporting Normativity}

Normativity is defined as the degree to which actors regard the rules of a reporting regime as binding (Chauvey et al., 2015) and in relation to corporate reporting requirements, encapsulates the complex system of legislation, associated guidance and NGO activities that condition corporate attitudes and behaviour (Bebbington et al., 2012). Normativity research suggests that formal legislation alone, may not be enough to establish required reporting norms (Bebbington et al., 2012). It has been argued that stronger legislation is needed to drive firms towards fully transparent disclosure (LeBaron \& Rühmkorf, 2017), but studies of normativity in environmental (Bebbington et al., 2012; Chelli et al., 2018) and social (Chauvey et al., 2015) reporting contexts, suggest a complex situation where the perceived legitimacy of a governance regime appears to be more important than legislative strength.

Arguing for stronger legislation, LeBaron and Rühmkorf (2017) cite differences between the relatively light reporting requirements of the UK MSA and the stringent requirements of the UK Bribery Act, 2010 which extend even to extraterritorial criminal corporate liability. The Bribery Act is found to have resulted in significant policy and practice changes that firms have propagated into supply chains (LeBaron \& Rühmkorf, 2017). However, in what Chelli et al. (2018) refer to as a seminal paper, Bebbington et al. (2012) observed higher reporting standards in a weak legislation UK reporting regime than with a more stringent legislation Spanish comparator. This was attributed to the higher legitmacy accorded to the UK reporting guidance, despite limited legislative support. The perceived legitimacy of the guidance standard led to higher reporting standards becoming normalised (Bebbington et al., 2012), suggesting that even in weak legislative regimes, normativity can be achieved through the non-statutory governance elements. This wider governance perspective is typically overlooked in modern slavery research.

Even where more stringent legislation does drive an apparent increase in reporting compliance, this may be merely symobolic rather than substantive in content. Substantive disclosures describe concrete actions through which corporate processes are aligned with societal expectations, whereas symbolic disclosures represent attempts to influence stakeholder perceptions only (Michelon et al., 2015). Chelli et al. (2018) noted significantly higher normativity in a more highly legislated French regime (the Nouvelles Régulations Économiques (NRE) 2001-420) compared with a Canadian comparator, but found reports were not substantive. Their conclusion was that stronger legislation had not led to more normativity in substantive reporting, which in turn, explains observations that the NRE reporting objectives remain largely unmet (Chauvey et al., 2015).

Low normativity is seemingly evident in modern slavery reports, where the established norm is one of minimal compliance featuring symbolic disclosures (Birkey et al., 2018). These sub-optimal norms have become decoupled from envisaged ethical standards (Huq \& Stevenson, 2020), suggesting low legitimacy of the MSA reporting regime Firms with complex, multi-tier supply chains need to manage supply networks that become exponentially large, where costs may be considerably larger than regulator estimates (Swift et al., 2019). Firms also may not have full control of upstream relationships (Gold \& Heikkurinen, 2018) or may be concerned about transparency-related intellectual property risks (Marshall et al., 2016). Whilst firms grapple with implementation costs and complexity, governments, through light-touch transparency legislation, have largely subcontracted regulation to firms (New, 2020) potentially resulting in ambiguous or ambivalent signalling from a firm's perspective. Although ultimately, stronger legislation may be needed to force firms into more substantive discovery and reporting action, the effectiveness is still likely to depend on 
normalised perceptions of the legitimacy of the governance regimes. Legitimacy perceptions may not apply uniformly across a regime, so research needs to establish how reporting performance varies for different reporting elements so that improvements may be targeted at specific reporting deficiencies.

\section{Empirical Research on Modern Slavery TISC}

Studies of business responses to modern slavery TISC legislation are now emerging, through studies of retailers' reporting responses to the Californian act (Birkey et al., 2018), FTSE350 firms in the UK (Flynn, 2020; Flynn \& Walker, 2021), fashion sector firms in the UK (Benstead et al., 2018; Stevenson \& Cole, 2018; Voss et al., 2019), the UK food and tobacco sector (Monciardini et al., 2021), and ASX100 firms in Australia (Christ et al., 2019).

Analysis of reporting quality, thus far, focuses either on thematic analyses exemplifying the variety in reported modern slavery practices (e.g. Stevenson \& Cole, 2018; Voss et al., 2019), or on assessing headline correspondence with reporting guidance (e.g. Christ et al., 2019; Flynn, 2020). Most studies also include an assessment of statutory conformance because, despite the relative lax requirements, many firms still are non-compliant. Flynn and Walker (2021) observe that 43 of the UK's FTSE350 firms had not published a report at all, whilst Voss et al. (2019) find even lower publication rates in the fashion sector, with non-conformance noted in $40 \%$ of firms that did publish a statement. The extent to which published statements reflect government guidance has so far been assessed only at a headline level, through searches for indicator phrases that suggest each element prescribed by the Section 54 guidance is covered to any extent (Flynn, 2020), or sentence counts for reporting themes (Christ et al., 2019). There is an attendant risk with such assessments that correspondence with guidance may be overstated where even superficial statements are detected and included in summary data. Superficial alignment with guidance propagates symbolic structures that create an impression of legal and regulatory compliance regardless of their effectiveness (Monciardini et al., 2021).

\section{Sub-optimal Norms}

These empirical studies find considerable variance in the depth of firms' modern slavery reports (Christ et al., 2019; Stevenson \& Cole, 2018; Voss et al., 2019), but consistent indicators are apparent, of convergence around suboptimal reporting practices through tactics such as the use of third party audits and codes of conduct (Benstead et al., 2021; Cole \& Aitken, 2019), supplier contract mechanisms (Monciardini et al., 2021), and stakeholder reassurance though association with esteemed organisations (Meehan \&
Pinnington, 2021) or professional bodies (Flynn \& Walker, 2021). The paucity of evidence of genuinely substantive modern slavery reports (Birkey et al., 2018), indicates that emergent norms are, as Huq and Stevenson (2020) suggest, decoupled from envisaged policy standards.

If policy objectives for modern slavery reporting are to be achieved, then it is important that the legitimacy of the reporting regime (as distinct from organisational legitimacy) is accepted by business, such that substantive reporting standards become widely adopted and normalised. This is unlikely to result from enactment of stronger legislation alone (Bebbington et al., 2012) and will depend upon attitudes and behaviour conditioned by all elements of the governance regime. However, in order that the relative merits of stronger policy enforcement, further legislation, and extended guidance can be weighed, appraisals of current reporting performance must go beyond headline conformance to distinguish substantive reports from symbolic returns across each reporting area. Typically, reporting guidance is extensive and multi-themed (e.g. AuGov, 2018; Harris, 2015; HMG, 2018), so studies need to consider which aspects of each theme are more, or less, effective and how these are captured in the governance regime. By adopting and developing a normativity perspective, research can be extended beyond analysis of statement quality and conformance, to consider what changes in the reporting regime may increase firms' perceptions of the legitimacy of that regime.

\section{Method}

This study assesses the quality of UK government suppliers' modern slavery statements to indicate the extent to which corporate responses to the UK MSA, 2015 (MSA) reflect policy ambitions and the implications that the findings have for policy makers and practitioners. The UK is an ideal setting for the study because the MSA is long enough established such that firms should have experience arising from several reporting cycles, with detailed enough guidance (HMG, 2018) that there is a comprehensive standard against which responses can be evaluated. Additionally, the Ethical Trading Initiative (ETI), an independent alliance of businesses and non-government organisations (NGOs), has produced an assessment framework, through which firms' responses can be evaluated (ETI, 2019). The ETI framework is a particularly appropriate tool for this study because as well as establishing an extensive set of evaluation criteria, aligned to the government guidance, it also defines three quality levels to identify the strengths (or weaknesses). The framework is based on an educate-and-assess philosophy through which firms learn how to comply better with the aims of the legislation and assess progress. 
The dataset (Appendix 1) consisted of modern slavery statements for 95 UK central government suppliers, as advised by the Crown Commercial Service (CCS), covering significant framework-agreement suppliers and 34 strategic (multi-departmental) suppliers. CCS, an executive agency of the Cabinet Office, is the biggest public procurement organisation in the UK with over 18,000 customers, and leads on procurement policy on behalf of the UK Government. The 95 suppliers cover a broad range of product and service categories, from multiple sectors. Statements were assessed by two researchers in two randomly allocated groups. Fifty were assessed by researcher A and forty-five by researcher B.

The analysis consisted of three phases: a pilot phase to ensure correct application of the framework, secondly, the statement assessment phase in which individual statements were analysed, and thirdly, a theoretically informed analysis of the combined dataset, including analyst reports to explore assessment criteria most closely associated with discovery, disclosure or transparency. The research was conducted between June 2019 and April 2020.

\section{Pilot Phase}

The ETI framework is relatively new and, previously, has mainly been used to assess ETI members' statements. Many of the criteria defined by the framework are qualitatively assessed so a pilot phase was included to increase consistency in interpretation. Analysts initially collaborated on three assessments to develop a common understanding of the framework and its assessment criteria. A review meeting was then held with CCS to ensure that suppliers' statements were being reasonably interpreted in line with CCS' experience with those suppliers. A second meeting was then held with all project stakeholders, including the ETI framework author, to ensure that the tool was being applied as intended and that interpretations appeared reasonable (face validity).

\section{Statement Assessment Phase}

In addition to the main ETI framework assessment, two checks for statutory compliance were also made: MSA Section 54, clauses 6 and 7 requiring statements to be signed by a director and accessible from the firm's internet homepage. These compliance checks indicate the level of statutory compliance for the sample, enabling trends in compliance to be monitored in future studies. The ETI framework contains three categories of data (see Table 1): firm attributes, overarching principles and key content descriptors. The six overarching principles were each rated on a 5-point qualitative scale (None; Very little; Partial; Reasonable; Good). The key content descriptors (criteria), however, form the most substantial part of framework. These criteria are structured in accordance with the six reporting topics defined by the MSA Section 54 guidance. A total of 42 assessment criteria are defined across the six topics ( $a v=7$ per section). Each of the six sections' key content descriptors are accompanied by a page of indicative information that should be included for that section. A statement is graded by identifying the relevant part(s) of a statement exemplifying the indicative information and assessing these against each of the key content descriptors. An example of the key content descriptors and indicative information guidance, for Section 6 training and capacity building, is given in Appendix 2.

The content descriptors are structured by level within each of the six sections. Level 1 represents minimal (basic) conformance with government guidance, whilst levels 2 and 3 recognise superior performance in which past and planned actions indicate genuine attempts to understand and manage modern slavery risks in supply chains. A response must meet the criteria for lower levels for it to be considered for higher levels.

A statement was expected to cover the majority, but not all, of the indicative information sources for each descriptor. Statement sections were considered to have met the criteria for a level where relevant information (defined by the

Table 1 Assessment framework breakdown

\begin{tabular}{|c|c|c|c|}
\hline Framework element & Framework supporting definitions & $\begin{array}{l}\text { Output analytical notes: } 1 \text { table } \\
\text { per MSS }\end{array}$ & $\begin{array}{l}\text { output Summary table: } 1 \text { row per } \\
\text { MSS }\end{array}$ \\
\hline (A) Attributes $(n=6)$ & N/A & Attribute values $(n=6)$ & Firm name \\
\hline (B) Overarching Principles $(n=6)$ & Definition sheet & $\begin{array}{l}\text { Analyst notes for each principle } \\
(n=6)\end{array}$ & 5-pt ratings ('none' to 'good') \\
\hline \multirow[t]{3}{*}{$\begin{array}{l}\text { (C) Main assessment criteria } \\
(n=42)\end{array}$} & $\begin{array}{l}\text { Key content descriptor sheets: ( } \\
\text { per Sectioin } 54 \text { topic, } n=6) \text { mul- } \\
\text { tiple criteria per sheet }(\mathrm{av}=7) \&\end{array}$ & $\begin{array}{l}\text { Analyst notes for each criterion } \\
\quad(n=42)\end{array}$ & $\begin{array}{l}\text { Rating 4-pt scale (Level 0-3) } \\
(1 \text { per Section } 54 \text { topic, } n=6)\end{array}$ \\
\hline & $\begin{array}{l}\text { Information sheets: typical } \\
\text { sources expected for each topic }\end{array}$ & & \\
\hline & & $\begin{array}{l}\text { Analytical notes table ( } 1 \text { per MSS, } \\
54 \text { cells) Total } 5130 \text { cells }\end{array}$ & $\begin{array}{l}\text { Summary table ( } 12 \text { scores per row) } \\
\text { Total } 1140 \text { cells }\end{array}$ \\
\hline
\end{tabular}


information sources) was provided in sufficient detail to be considered substantial. Allowance for a smaller number of sources was made where statements provided greater detail for those sources. Responses for each level of each section, were classified as substantial where significant detail was included for at least half of the information sources, or where more sources were covered but only at a moderate level of detail.

The nature of this qualitative evaluation dictated the need for a pilot phase and the use of two analysts that could be compared through interrater checks. For each firm, the ratings data (for overarching principles and Section 54 topics) were recorded in a row in the summary ratings table. Analyst notes for each firm's assessment were documented using a structured ETI template covering the 54 fields of the assessment. Each cell was marked either as "None" where no relevant information was encountered, or annotated with a summary of the related finding or a relevant quotation from the statement.

\section{Quality Checks}

A Mann-Whitney (Armstrong et al., 1997) interrater assessment was undertaken to indicate the generalisability of the results. The use of two analysts, with limited subject matter knowledge, provided an opportunity to assess whether, through careful application of the tool, relatively inexperienced analysts could achieve similar, comparable results. The null hypothesis was that there would be no difference in the quality-level scores between the two researchers. Tests were undertaken for all six sections comprising the main quality assessment. Although subjectively assessed, the enumerated nature of these elements marks them as suitable for interrater comparison (Armstrong et al., 1997). The gaps between the three performance 'levels' in the ETI framework cannot be considered to be equal, so data were considered to be ordinal rather than scalar. Based on extant research (e.g. Birkey et al., 2018; Voss et al., 2019), the prior expectation was that few firms were likely to be exhibiting performance above level 1, and therefore the non-parametric Mann-Whitney test was used.

Differences in two of the six dimensions, Section 4 (Due Diligence) and Section 6 (Training), were subject to further investigation and discussion with the ETI framework author to inform interpretation of those results. Differences were attributed to the high proportion of borderline cases for those two sections (between Level 0 and Level 1). It was concluded that the average performance lay somewhere between zero and one, but that the interrater differences were self-cancelling in effect. These rigour tests illustrate the difficulties of achieving consistency with subjectively interpreted assessments, and it must be emphasised that the framework does not claim to achieve consistency at this level of granularity.

\section{Collective Analysis and Theoretical Sensitivity}

Whereas in phase two the 95 statements were analysed individually, in the third phase, the combined data corpus was scrutinised thematically to develop theoretical insights. The data corpus consists of the 95 modern slavery statements, individual analyst reports for each assessment, and a collated results table summarising all ratings (Fig. 1). The 95 analyst reports constitute analytical memos (Charmaz, 2014; Saldana, 2016) that are treated as data and subject to theoretically oriented analysis leading to the production of further theoretical memos through a reflexive process (Saldana, 2016). The structured template, used to record analyst notes for each statement, enabled cross-case analysis for any criterion or principle to be thematically explored. In this phase, theoretical sensitivity was developed through cycles of thematic exploration of data and the literature (Glaser, 1978), in which data were reviewed against literature on transparency and reporting normativity to develop theoretical insights. Credibility at this stage was assured through a formal, recorded discussion with the ETI framework author, to ensure that interpretations resonated with the field and exhibited fit, relevance, modifiability and generalisability (Glaser, 1978).

\section{Findings}

This study utilised the ETI modern slavery framework to assess the extent to which corporate responses to the UK MSA indicate that policy ambitions are being met and what implications the findings have for policy makers and practitioners. Three elements comprise the findings: firstly, a short summary of legal compliance, secondly, the content quality ratings are summarised for the six Section 54 topics, and thirdly, a theoretically oriented analysis of data relating to transparency themes, which forms the basis for the discussion.

\section{Legal Compliance Summary}

Although the detailed analysis focuses on content quality, conformance checks against basic legal requirements (naming and positioning on the homepage and compliant signature), were also undertaken (Table 2) to enable sample comparison with previous studies (e.g. Flynn, 2020; Stevenson $\&$ Cole, 2018; Voss et al., 2019). From the sample of 130 government suppliers, 95 statements were readily retrieved. Readily retrieved meant that the named contracting organisation had a direct link to a statement on its website, or had a 
Fig. 1 Relationship between the framework and analytical outputs

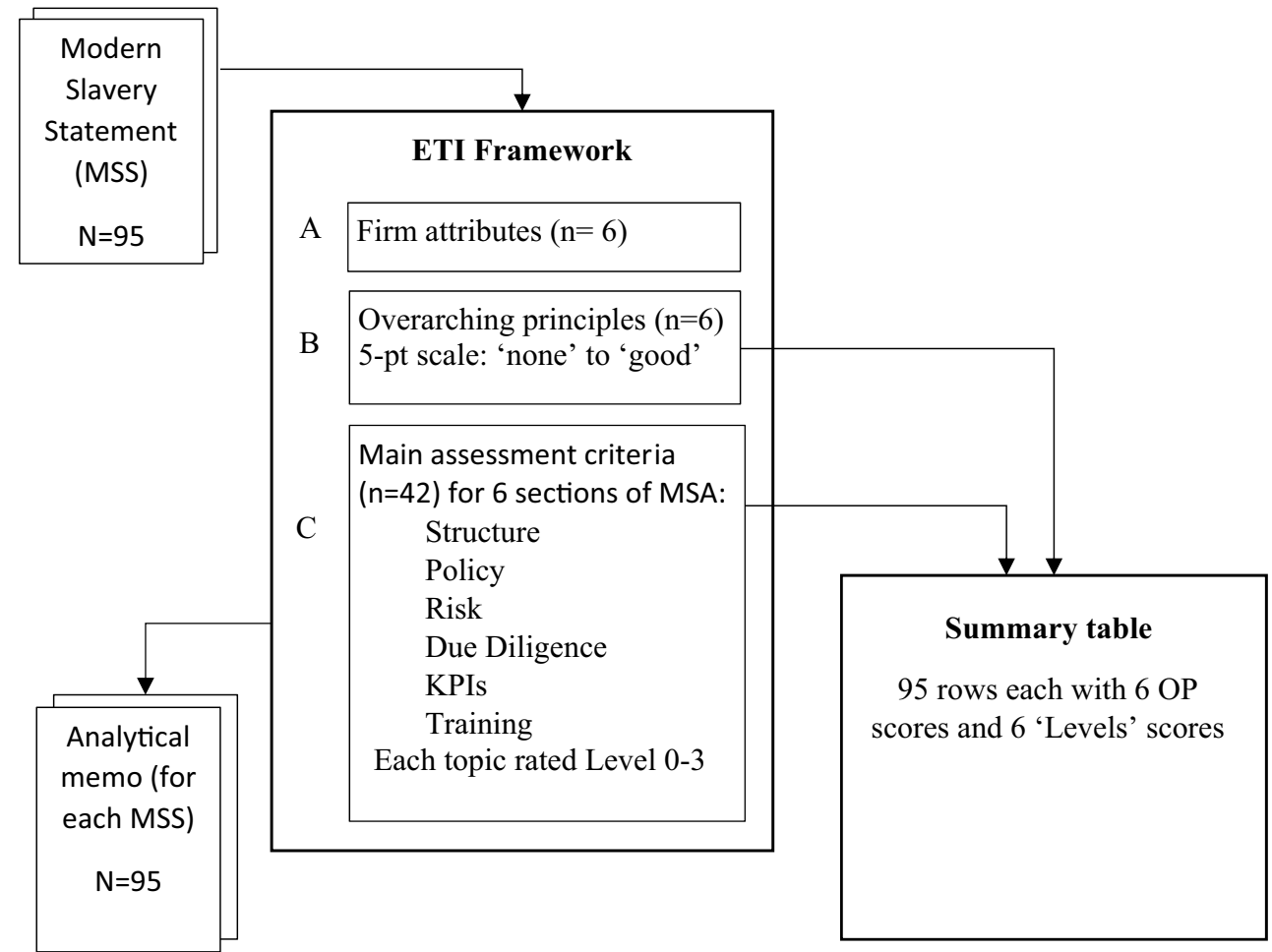

Table 2 Summary of legal compliance

\begin{tabular}{lrl}
\hline & Total & Percent \\
\hline Sample (including non-retrievals) & 130 & \\
Readily retrieved statements & 95 & 73 \\
Compliant naming and positioning on & 66 & 77 \\
$\quad$ homepage & 77 & 81 \\
Compliant signature & & \\
\hline
\end{tabular}

link or directions to a statement on its parent website, or had an indirect link on its homepage to a page likely to contain the statement. Others may still contain legally compliant statements on parent company homepages but resources were not dedicated to track such links that were not obviously indicated.

\section{Statement Content Quality}

The ETI assessment framework defines three levels of performance, which are designed to recognise and encourage progression in modern slavery practices for each of the six sections defined by the government's guidance on Section 54 statements (HMG, 2018). The results in Table 3 indicate that the majority of firms' statements address structure and policy sections at level 1. Quality of statements in the other 4 sections is much weaker, with over $30 \%$ of firms having failed, adequately, to address the section. Very few firms achieve level 2 or above in any of the six sections.
Table 3 Section 54 results by statement section

\begin{tabular}{lllllll}
\hline $\begin{array}{l}\text { Section 54 } \\
\text { reporting ele- } \\
\text { ment }\end{array}$ & \multicolumn{2}{l}{$\begin{array}{l}\text { Level 1 or better } \\
(n=95)\end{array}$} & & \multicolumn{2}{l}{$\begin{array}{l}\text { Level 2 or bet- } \\
\text { ter }(n=95)\end{array}$} & $\begin{array}{l}\text { Mann-Whit- } \\
\text { ney } p \text {-value }\end{array}$ \\
\cline { 2 - 3 } & Total & $\%$ & & Total & $\%$ & \\
\hline Structure & 82 & 86.3 & & 6 & 6.3 & 0.049 \\
Policy & 89 & 93.7 & & 3 & 3.2 & 0.089 \\
Risk & 42 & 44.2 & 3 & 3.2 & 0.716 \\
Due diligence & 61 & 64.2 & 2 & 2.1 & $0.000^{*}$ \\
KPIs & 31 & 32.6 & 0 & 0.0 & 0.315 \\
Training & 62 & 65.3 & 3 & 3.2 & $0.000^{*}$ \\
\hline
\end{tabular}

*Significant interrater difference

Overall, these findings indicate that many government suppliers are not meeting even the minimum expectations of the Section 54 guidance, as assessed by level 1 of the framework and are therefore engaging in symbolic reporting. Currently, only one firm (Vodafone), with 4 sections rated at level 2 or better, may be considered to be producing substantive reports reflecting the ideals underlying the legislation and associated guidance. No firm achieved Level 2 or 3 for all six topics, each of which is discussed in the following sections.

\section{Structure}

Few firms go beyond a high level description of divisional structure and many fail adequately to describe their modern 
slavery governance processes. Weak supply chain mapping processes or intentions were a common feature throughout the sample. Opus Energy (part of the Drax group) achieved a level 2 rating because the group structure, business activities and governance structure are extensively documented.

Our Group Ethics and Business Conduct Committee ("EBCC"), a subcommittee of the Executive Committee, oversees our modern slavery programme. An annual report on the activity and decisions of the EBCC is provided to the Audit Committee, which comprises executive and nonexecutive directors [Drax]

The Drax statement also provides above average information on the breakdown of its coal and biomass sourcing by country of origin, though the lack of location detail on subsidiaries were a limitation.

\section{Policies}

Policies are relatively easily referenced in statements, and most firms do, but few provide detail on the content or enforcement of their policies. Firms may just list policies, but better examples, such as Pitney Bowes' supplier code of conduct, provide more extensive descriptions with references that indicate a more substantial policy.

(Suppliers) agree not to engage in any form of human trafficking or slavery ... All employment must be voluntary and legal. (Code page 4.) ... Every supplier should have a policy that prohibits inappropriate conduct and a process for ... investigation and resolution. (Code page 7.) (Pitney Bowes)

\section{Risk Assessment}

The standard of reporting across the remaining four sections was much lower than for structure and policies, with risk assessment attracting particularly low scores (Table 3). Few identify high-risk areas of their business, or risk assessment processes. Despite the established prevalence of modern slavery globally, many large firms believe there to be a low risk of issues in their supply chains.

We continue to believe that our exposure to the risks of modern slavery is low ... No instances of modern slavery have been identified during the year in any of our sectors in 2018/19 (Babcock)

Service firms, such as PwC, with much simpler supply chains may be more forthcoming but still downplay risks, in this case by associating risk with spend, rather than supplier profile.
... four hotspots (information technology, food, support staff uniforms and corporate merchandise) totalling less than $6 \%$ of $\mathrm{PwC}$ overall procurement this year.

\section{Due Diligence}

Approximately two-thirds of firms make some reference to due diligence approaches but many are superficial with little assessment of the relevance or effectiveness of checks in a modern slavery context:

We regularly undertake appropriate checks in respect [of] our employees and contract workers through CRB checks, referencing and also validation of personal information (Whistl)

Vodafone were the only firm to achieve a level 3 score for their highly comprehensive and open description of processes including detailing factors used in a three-stage supplier selection process, and extensive descriptions of monitoring and auditing processes that include worker surveys specifically linked to modern slavery risks.

... sections related to modern slavery risks are focussed on working hours and overtime, as these are often proxy indicators for a broad range of other labour rights issues (Vodafone).

\section{Effectiveness and KPIs}

Less than 33\% of firms exhibited even a basic level of Key Performance Indictors (KPIs) (Table 3). Many statements made no mention of KPIs or metrics, or of related processes for data collection, evaluation or action. Where KPIs are discussed, there is a shortage of detail, especially quantitative. Opus Energy (Drax) list six KPIs but with no indication of the numbers of suppliers engaged, and no enumerated targets. Action relating to the KPI "Steps taken to upskill our high-risk suppliers" is vaguely reported as:

Our Sustainability team have continued their programme to promote modern slavery awareness when conducting biomass supplier site visits (Drax)

\section{Training and Capacity Building}

A few sector-leading firms demonstrate leadership and commitment through well-developed training programmes and even sector-level collaborative initiatives:

... we developed a bespoke e-learning module in 2017. We also collaborated with Stronger Together, the CIOB and Surrey County Council in 2017 to produce 
the 'Concrete' video which was filmed on one of our sites (Willmott-Dixon)

However, many present vague statements indicating a lack of modern slavery specific training.

We train our staff on ethics and compliance with our values, directives and processes (Mott MacDonald)

Few firms report training figures, even for directly employed staff, further exemplifying the paucity of metrics associated with modern-slavery reporting.

\section{Transparency Assessment}

The third phase of the study examined the full dataset, including the analytical memos and the master summary table, to explore how commensurate current statements are with policy ambitions of open and active management of modern slavery issues in firms' supply chains. In this theoretically oriented phase, data were examined for insights relating to transparency and the associated themes of discovery and disclosure. The normativity literature was engaged to increase sensitivity towards substance verses symbolism in source data. The presentation of findings is organised around transparency-oriented themes and includes references to particularly relevant criteria in the assessment framework.

\section{Transparency}

In relation to the framework's Overarching Principle (OP) Openness and transparency, of the 95 statements assessed, only 9 achieved the rating 'very little' whilst 80 were considered to demonstrate no meaningful transparency at all. No statement was rated as 'good'. The best examples are provided by Hewlett Packard (HP) and Microsoft, who exemplify reasonable discovery and disclosure practices by providing some numbers on audits undertaken and by disclosing numbers of issues uncovered by audits. Although the details of issues uncovered are not provided, these firms at least demonstrate some transparency willingness.

Eight suppliers were found to have indicators of modern slavery, including charging of recruitment fees and one also had passport and personal document withholding. Two of these suppliers ... were also associated with media reports ... of modern slavery (HP)

\section{Discovery}

Framework criterion $\mathrm{C} 7$ assesses the discovery activity of supply chain mapping. This activity encourages firms to establish the identity and location of upstream members of their supply chains and enables them to assess and manage risks associated with those firms. As 93 of the 95 assessed firms neither report details of previous supply chain mapping activities, nor report on future plans to do so, it appears that firms are not adequately prioritising discovery activities. Only one supplier indirectly alluded to an intention to map its supply chains, but even here the timescale and commitment seemed aspirational, rather than explicit.

We plan to ... benchmark available tools, to facilitate the mapping of more challenging supply chains (Drax)

Instead, firms often describe auditing activities they have commissioned, but typically with little or no link to any improved outcomes expected from such activities. Many of these references are not explicitly tied to modern slavery.

... undertake audits on those where we consider the exposure to be greatest (Carlisle Security)

... Include effectiveness of controls and training within annual operational ISO9001 audit (Interact Medical)

More positive examples include details specific to modern slavery, and identify a valuable purpose for an audit.

We conduct audits on the accommodation facilities and worker welfare standards of agency supplied, and subcontractor, staff (Interserve)

Firms' processes and appetite for identifying risks in their supply chains are assessed through criterion C17: Most salient risks. Some firms go as far as identifying sectors or locations where they most anticipate problems, but few provide any detail on discovery processes or detection success. In the absence of detailed structural maps of supply chains, firms emphasis is placed on risk and responsibility transference up the supply chain.

...concluded that the most significant risks remain in our material and subcontract procurement (Balfour Beatty)

The key risks identified are in contractor materials sourced outside of the EU and where ... migrant labour used (BAM Construct UK)

The main Modern Slavery risk within our subsidiaries' operations stems from bringing workers employed by other companies ... (Interserve)

\section{Disclosure}

Firms generally scored much higher against OP4: Reporting detail and evidence, than for the openness and transparency principle, with 35 firms assessed at the mid-point rating, but still with 25 at the lowest. Only two were assessed as good. Firms typically are prepared to disclose information about 
their policies (criterion C10: List relevant policies). Firms' own policies do not pose a discovery challenge, and risks associated with disclosure are likely to be low, so where firms are reticent to release details, they may be suspected of having poorly developed or non-specific policies. Firms such as ICS provide a list of policies, but by not relating them specifically to modern slavery, the information is interpreted as distraction (Marshall et al., 2016) rather than meaningful disclosure. Firms also frequently cite codes of conduct but again lacking detail, or links to any measures or outcomes.

These [policies] set out our position of zero tolerance of modern slavery and human trafficking in any form in our business and supply chain. (Kier)

Policies should be specific to modern slavery and be publicly disclosed. Many firms do list relevant policies on topics such as whistle blowing and recruitment verification policies but few publish the full policy. Some, however, such as Serco Group plc, established the relevant of their policies and codes of conduct and make them publicly available.

Few firms disclosed meaningful information in relation to KPIs. Criteria relating to KPIs have both discovery and disclosure elements. For criterion C31: Existing KPIs and their relevance to modern slavery, less than one-third (31 of 95) of the firms sampled reached even level 1, with 62 making no material statement at all. For the related criterion C32: Proposed new KPIs to measure progress on MS commitments, no firms in the sample were assessed at level 2 and few revealed plans for developing Modern Slavery specific KPIs. One firm apparently recognised the issue and planned to address it, however, the subsequent statement (published April, 2020) contained just a single KPI on training, with no further mention of KPIs, suggesting a reduced appetite for formal measurement.

Whilst we have been monitoring progress in our due diligence programme, we have not yet set specific KPIs. We will set appropriate KPIs during 2019 (Travis Perkins plc)

\section{Disclosure of Unknowns}

Framework criteria C3: What is not known and C4: Plans to address unknowns provide an unusual perspective by focussing on gaps in firms' knowledge relating to their supply chains and associated modern slavery risks. Through these criteria, firms are given credit for their willingness to disclose knowledge gaps and their plans to address those gaps. No firms were fully open about their knowledge gaps and very few revealed any explicit plans to address gaps. Some firms went as far as acknowledging that modern slavery is likely to exist somewhere in their supply chains. Such statements were considered to be implicit, rather than an explicit recognition of unknowns.

We are aware that risks arising from modern slavery and human trafficking can apply anywhere in our operations, whether through direct employment, subcontracted employees or the supply of materials (Kier) Many of our suppliers are mature and established organisations who accordingly take a thoughtful and risk-based approach to Modern Slavery, but we recognise that not all our suppliers may be so committed (KPMG)

Language framed around awareness and recognition may be intended to convey an impression of informed decision making, but the near absence of detailed substance instead suggests a tacit recognition of unknowns.

\section{Assessment Summary}

Modern slavery discovery processes are poorly established in almost all firms in the sample. Poor detail is provided on risk assessments, no supply chain mapping reports are provided, and very poor engagement with Section 54 guidance on KPI reporting is evident. In relation to risk, KPIs, and supply chain mapping, the indication is that discovery, rather than disclosure, is inhibiting transparency. Whilst recognising that corporate reports may be weakly tied to corporate action (Gold \& Heikkurinen, 2018), such that promised actions remain unrealised or reported actions are overstated, it seems likely that firms would wish to take credit for the limited actions they have undertaken. We therefore interpret low incidence of reports on supply chain mapping, KPIs and training as being indicative of weak action. The reviews of unknowns, revealing almost no explicit acknowledgement of gaps in knowledge, with only a few firms recognising that issues are likely to exist in their supply chains, is indicative of constrained disclosure. Disclosure of unknowns represents an additional dimension to disclosure not typically covered by the transparency literature.

The widespread achievement of a level 1 standard for sections on organisational structure and modern slavery policy, contrast with relatively low numbers of firms achieving even this basic standard for the remaining four sections defined by the UK's MSA. ETI framework level 1 performance characterises minimal compliance with the guidance and therefore we consider performance at or below this level to constitute symbolic rather than substantive reporting. Only performance at level 2 or 3 is genuinely substantive. 


\section{Discussion}

This study evaluated the content of 95 UK government suppliers' modern slavery statements to assess the extent to which corporate responses to the UK MSA indicate that policy ambitions are being met, and the implications the findings have for policy makers and practitioners. With modern slavery reporting, discovery processes are poorly established in almost all firms in the sample, suggesting that discovery is a bigger issue than disclosure. In this study, we also extend previous conceptions of the disclosure dimension of transparency, by recognising two facets to disclosure. By recognising the importance of disclosure of unknowns, as well as known information, we derive a new model of transparency (Fig. 2), through which additional strategies for improving transparency are discussed below, along with their implications for governance regime normativity.

The few reports of supply chain mapping exercises and KPI management, indicate issues relating to discovery rather than disclosure. SSCM transparency literature focuses on disclosure strategies (e.g. Chen \& Slotnick, 2015; Marshall et al., 2016) to account for report content, but in a modern slavery context, there is little evidence to indicate that firms have even gathered sufficient data, on which to base a disclosure strategy. Most organisations seem, largely, to be avoiding detailed and potentially expensive analyses of their supply chains. Whilst disclosure strategies are risk judgements (Chen \& Slotnick, 2015), the acknowledged expense associated with activities such as supply chain mapping (Doorey, 2011), suggests that discovery willingness is cost related. Firms face cost and risk disincentives to transparent reporting, both of which need to countered by policy makers.

As well as deciding how much to report of the information they have discovered, the ETI framework also encourages reporting of known unknowns. Reporting of unknowns represents an extension to transparency logic. Transparency logic argues that increased public dissemination of

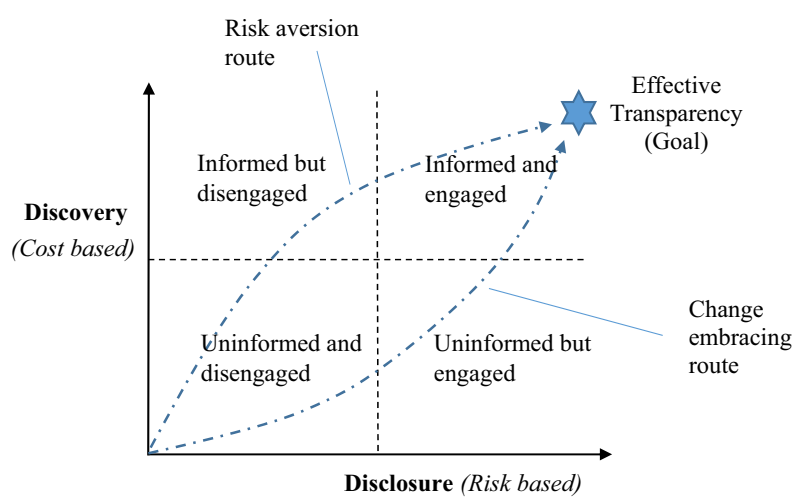

Fig. 2 Incentivising effective transparency information relating to a phenomenon, enables greater stakeholder scrutiny, which in turn will encourage more substantial action by the firm (Monciardini et al., 2021). We posit that the publication of known unknowns, along with commitments to filling those information gaps, will enable increased stakeholder scrutiny encouraging firms to honour commitments to closing those gaps.

Public policy incentives therefore need to counter-balance firms' costs and risks relating to modern slavery statements and encourage (or mandate) reporting of unknowns where information gaps exist. We represent these challenges through a model of reporting costs and risks, in which the management of disclosure of unknowns can provide policy makers with an alternative policy route to their goal of open full transparency. In Fig. 2, the goal is the top-right point, in which informed and engaged firms are extensively informed about their supply chains and committed to sharing that information openly.

Firms performing at, or below, level 1 of the ETI framework are uninformed and disengaged (Fig. 2) and need to be incentivised with benefits that outweigh the costs and risks of transparency, but not necessarily with equal emphasis. Firms do not need to follow the straight-line route from disengagement to full transparency and may prefer to take a cautious approach by undertaking thorough investigation of modern slavery in their supply chains before any decision on disclosure. Nike followed this route, in a CSR context (Doorey, 2011). Initially, despite having gathered information on their supply chains, they were reluctant to disclose their findings (informed but disengaged, Fig. 2). Several years later, the firm surprised the market with a change of strategy and openly published their supply chain data. Firms following this route incur significant discovery costs before any apparent improvement in transparency.

Existing theoretical models concentrate on disclosure strategies (e.g. Chen \& Slotnick, 2015; Marshall et al., 2016) that represent a firm's risk aversion (Fig. 2). The more riskaverse the firm, the more accentuated the (left hand) curve, and the more likely it is that the firm will remain in the informed but disengaged quadrant. For risk-accepting firms, this curve flattens towards a straight line (from bottom-left to top-right), where firms publish all additional data they collect.

Recognition that disclosure should also include disclosure of unknowns, opens a further route of influence for government policy implementers, one through which firms' commitment to transparency policy can be manifest before they incur the full costs of discovery. Firms that embrace the change (right-hand) route in Fig. 2, will make public disclosures of limitations in modern slavery statements that will increase scrutiny of their subsequent statements, encouraging them to improve their discovery processes in the meantime. These firms are uninformed but engaged (Fig. 2), 
and this engagement is recognised at Level 2 on the ETI framework. Whilst public policy implementers will need to be sensitive to firms that use disclosure of unknowns as a tactic to delay discovery spending, they nevertheless have an opportunity to recognise and reward firms that make open declarations of information gaps along with timed commitments to closing those gaps.

The goal of open transparency (top-right of Fig. 2), represents the point where normativity is established such that firms recognise the reporting governance regime as binding (Bebbington et al., 2012). The low overall standard of statements (at or below ETI framework level 1), echoing previous findings (Birkey et al., 2018), suggests organisations are employing strategic ambiguity (Meehan \& Pinnington, 2021) to render an impression of activity, rather than embracing substantive action. There are clear indications of convergence between statements, with patterns evident in most of the criteria, suggesting that organisations are normalising a standard. Convergence between statements is expected (Crane, 2013; Stevenson \& Cole, 2018) but indications are that rather than convergence being towards higher quality statements envisaged by policy makers, convergence is towards a minimal acceptable level, suggesting a "decoupling" from the envisaged policy standards (Huq $\&$ Stevenson, 2020). This symbolic reporting (Chelli et al., 2018) indicates low legitimacy in the prevailing governance regime (Bebbington et al., 2012).

Governance regimes extend beyond legislation to include elements such as guidance, leadership, training and scrutiny, therefore legislation is not the only 'tool in the box' for policy makers to achieve regime normativity. The government is also responsible for providing practitioner guidance, and as the head of its own supply chains is leading by example with a voluntary release of its own modern slavery statement (HMG, 2020). Importantly, it is also able to exert considerable commercial influence to encourage active discovery and open disclosure. Although public procurement has rarely been used to influence human rights cross-jurisdictionally (Martin-Ortega, 2018), central government procurement agencies have an opportunity to influence suppliers, with a global supply chain footprint, through the weighted scoring systems used in major tendering processes. Government suppliers are selected through controlled tendering processes with declared evaluation criteria typically leading to longterm contracts or framework agreements (upon which future contracts with specific public entities will be based). Tender processes, in which TISC performance forms a part of the scored evaluation, rather than being a mandatory gated element, has the potential to make TISC performance a contract winning rather than contract qualifying criterion.

In discussions on transparency, we must of course recognise the difference between reports and real action, to avoid the transparency fallacy (Gold \& Heikkurinen, 2018) where the two are conflated. We must also recognise that legislation alone will probably not yield the behavioural changes envisaged in modern slavery policy initiatives (Birkey et al., 2018). However, both improved reporting and improved behaviour depend on effective information discovery processes that enable subsequent action. To manage modern slavery effectively, firms need to take ownership of their supply chains. The common practices of outsourcing supply chain audits (often with scope constraints), and arms-length supplier management where modern slavery requirements are devolved through contract clauses alone, characterise firms adopting hands-off tactics. Outsourcing audits has been criticised previously (Doorey, 2011) and is inconsistent with the close, active management of supply chain data, upon which genuine transparency depends. A step change is required by firms before meaningful systematic investigations of supply chains are undertaken, and firms need to be prepared to invest in genuine modern slavery initiatives, such as multi-party collaborative audits (Benstead et al., 2021) to become truly effective. Normativity is achieved through a three-step process in which change entrepreneurs establish new standards which are subsequently copied and later internalised by followers (Bebbington et al., 2012). The government has an opportunity to demonstrate leadership through its own reporting processes and procurement practices. Increasing reporting governance regime normativity (Bebbington et al., 2012) provides an additional institutional pressure towards improved practice beyond the coercive pressure arising from stronger legislation. Ultimately, both are likely to be necessary to effect and maintain a step change in modern slavery reporting practice.

\section{Theoretical Contribution}

The study complements and extends transparency and disclosure literature (Hess, 2019; Marshall et al., 2016; Swift et al., 2019), with insights from a modern slavery context, where detection and assessment challenges, coupled with a complex legislative environment, act to compromise transparency. Firstly, our research suggests that in a modern slavery context, discovery is a more important issue than disclosure strategy. Firms have both cost and risk disincentives that need to be countered before substantive action will result. Secondly, the research highlights the importance of disclosure of known unknowns. Transparency is dependent on both discovery of relevant information and a willingness to disclose it. Typically, disclosure is discussed only in terms of available and analysed data, with little or no recognition of gaps in firms' knowledge. Disclosure of known unknowns, especially when accompanied by plans to rectify those gaps, represents a published commitment by a firm through which stakeholder expectations of future progress towards transparency will 
be raised. This more nuanced perspective, enables distinct disclosure policy decisions to be made, concerning available versus unavailable data, thereby extending typical unidimensional perspectives on disclosure (e.g. Marshall et al., 2016) and cases where data collection and disclosure are conflated (e.g. Chen \& Slotnick, 2015). This additional facet of disclosure also opens a new approach to achieving full transparency. Hitherto, disclosure strategies represent a balance between disclosing or withholding already gathered data (Chen \& Slotnick, 2015; Marshall et al., 2016), but the highlighting of unknowns recognises and additional strategic disclosure option (Fig. 2) which public procurers can exploit by rewarding firms that follow the risk-embracing route to transparency.

Though this enhanced conception of transparency, upon which the modern slavery reporting requirements are founded, we also contribute to literature on reporting regime normativity (Bebbington et al., 2012; Chauvey et al., 2015; Chelli et al., 2018). Normativity is defined as the extent to which actors regard the requirements of a reporting regime to be binding and embraces the processes and behavioural factors that determine a regime's legitimacy. The concept has been developed in relation to environmental reporting (Bebbington et al., 2012; Chelli et al., 2018) and CSR (Chauvey et al., 2015) but rarely applied to a modern slavery context (Birkey et al., 2018). This is the first modern slavery study to extend the concept by identifying two different routes to normativity in which either cost or risk is the dominant concern (Fig. 2). Normativity is produced through a 3 -stage process in which norms are established by 'norm entrepreneurs' and subsequently cascaded and internalised (Bebbington et al., 2012). The modern slavery reporting regime includes few statutory requirements and therefore has a high dependence on guidance and non-governmental scrutiny to achieve its aims. It is particularly important in this weak legislative regime that calls to strengthen legislation are supplemented by improved understanding of the additional levers through which reporting ideals can be established. Through the reporting-risk route, the study identifies how guidance and government buying power can be harnessed to reward firms that report their known unknowns and associated improvement plans. Increased openness on reporting deficiencies increases firms' commitment to continuous improvement, against which they can be held to account.

Finally, a contribution is made to methods for evaluating modern slavery statements. The quality of corporate disclosures depends on the semantic properties and meaning of the information disclosed, not just its quantity and apparent richness (Michelon et al., 2015). The use of the ETI assessment framework, featuring a wide range of specific evaluation criteria, combined with three performance levels, naturally encourages a more nuanced review of content quality within each reporting category, thereby extending earlier dichotomous distinctions (e.g. Birkey et al., 2018) between substantive and symbolic reporting. This finer grained analysis will also enable longitudinal assessments of incremental improvements in reporting performance.

\section{Policy and Practice Contributions}

This study has important implications for policy makers and practitioners. Modern slavery legislation generally, is considered to be weak (Birkey et al., 2018; LeBaron \& Rühmkorf, 2017) but with governments seemingly reluctant to extend legislation significantly, it is important to understand which aspects of the policy objectives most warrant further legislative support. Relatively small amendments may in this way, have the greatest impact. Transparency-based modern slavery legislation, is predicated on the belief that increased scrutiny, enabled by greater disclosure, will motivate firms towards active management of modern slavery risks in their supply chains. However, if transparency is compromised by discovery weaknesses, rather than disclosure reluctance, then the inhibitors to discovery tasks need to be directly tackled by legislators and policy makers.

Supply chain mapping is an important platform for transparency, yet only a very small proportion of firms in this study claim to have undertaken any meaningful mapping. Typically, those that do, have outsourced the activity, or utilised reduction logic to constrain the task (Meehan \& Pinnington, 2021). Unless firms gather relevant information, disclosure strategies become irrelevant. Legislators can tackle cost-related discovery weaknesses by mandating specific activities, such as supply chain mapping, thereby ensuring that all firms invest in substantive reporting practices. Governments, along with other customers, will face higher charges as suppliers inevitably seek to recoup their increased costs, but this levelling of the playing field will help to reduce the likelihood of responsive firms being at a competitive disadvantage compared with less ethical rivals. However, it is likely that standards will still vary considerably. Guidance and leadership have a role to play in establishing best-practices, though which currently sub-optimal norms (Birkey et al., 2018) can be realigned. However, public procurement practices ultimately may be the most effective influencing tool. Tendering and evaluation practices in public sector procurement provide the perfect opportunity for public procurers to reward firms with stronger modern slavery reports. These formal evaluation processes feature pre-defined scoring systems with an allocated marking range for each evaluated criterion. The allocation of even a small percentage of marks may be particularly effective in highly competitive markets, with small differences in commercial 
quotes, because modern slavery reporting may then become an important discriminating criterion.

The importance of encouraging disclosure of unknowns is also highlighted in this study. Improvements can be encouraged through each of the government's influencing mechanisms. A synergistic effect may result where consistency in message is supported by guidance and public practice and rewarded through public procurement practice. The tiered evaluation of firms' modern slavery statements against published criteria, allows policy makers also to reward intermediate performance. Rewarding firms' public recognition of informational weaknesses in their modern slavery discovery processes is proposed as an important step in committing firms to future improvement. Whether mandated by legislation, or encouraged through public procurement practice, open disclosure of missing data increases the public visibility of gaps and therefore, is likely to encourage firms to improve discovery processes to close those gaps. Scrutiny by contract managers and NGOs, of firms' progress in addressing previously acknowledged deficiencies, will be important in ensuring that commitments are met.

This study has implications for other legislative domains. The Australian MSA and the French Duty of Vigilance acts go further than the UK and Californian acts in specifying the topics that need to be covered in corporate reports, but detailed requirements still appear only in guidance. Analysis of statement detail in this study demonstrates that even in a context where detailed guidance is available, most companies will conform only with the minimum acceptable standard unless given incentives to do otherwise. The French and Australian acts are likely to have to be extended and be supported by non-legislative action to move firms beyond minimal compliance.

Finally, the data compiled provide an important baseline quality benchmark, against which, future performance improvements can be assessed and against which, other UK data sets may be compared. Other NGOs undertake assessments of modern slavery statements (e.g. BHRRC, 2019), but this is the first empirical study to apply a publicly accessible framework to assess the quality and substance of modern slavery statements. This will help the government to assess the extent to which guidance and supply chain influence can avert the need for more stringent legislation. This study has created a large comparator group against which ETI's own assessments of its members' statements can be contrasted. The utility of the framework in assessing firms' modern slavery statements has been demonstrated which should of interest to a wide group of stakeholders with interests in firms' ethical credentials, including investors, journalists, NGOs, and academics.

\section{Limitations and Further Research}

The UK context for the study provides a rich source of data for assessing corporate responses to modern slavery legislation because of the additional policy guidance issued by the government (HMG, 2018) enabling detailed assessment of statement quality. Work is now needed in collaboration with NGOs to adapt assessment frameworks to other similar contexts, such as Australia, to assess the effectiveness of the 2018 act compared with the 2015 UK act. The dataset used in the study is drawn from central government suppliers. These suppliers are likely to be subject to greater than average scrutiny and may not be representative of large firm performance as a whole. The study does not attempt to analyse performance variations within the sample (e.g., for different sectors). Expansion of the dataset would enable cross-sector comparisons to be undertaken that would enable specific sectors to be targeted for action.

The practice of outsourcing CSR audits has been criticised (Doorey, 2011) yet many instances were encountered in the modern slavery statements assessed in this study. Other recent research (Swift et al., 2019) indicates that firms can benefit significantly through efficiency improvements when they investigate and better understand their supply chains. An investigation of audit outsourcing was outside the scope of this study, but future research may investigate the reasons why firms outsource these analyses and establish whether they risk losing key insights that could lead to efficiency gains. This risk may be high if firms are outsourcing supply chain audits as a low-cost compliance option, rather than as a genuine foundation for ethical and efficiency improvements.

Finally, studies of modern slavery statements, even ones undertaking deeper assessments of statement content, are drawing inferences from firms' reports of action and plans for improvement, rather than analysing manager attitudes and actions within those firms. Further qualitative case study is now needed to understand the extent to which statements reflect the broader practices and culture within firms to access whether firms are truly changing their practices or superficially complying with legislative demands. 


\section{Appendix}

\section{Appendix 1: Sample summary by sector}

\begin{tabular}{lrl}
\hline Sector & $\begin{array}{r}\text { Number of } \\
\text { companies }\end{array}$ & $\begin{array}{l}\text { Sum of latest } \\
\text { reported turnover }\end{array}$ \\
\hline Telecommunications & 3 & $£ 44,308,008,000$ \\
IT & 12 & $£ 36,548,070,553$ \\
Construction & 9 & $£ 19,849,430,000$ \\
Outsourced activities & 4 & $£ 16,041,200,000$ \\
Consultancy & 5 & $£ 14,260,943,000$ \\
Engineering & 4 & $£ 7,486,998,000$ \\
Recruitment & 21 & $£ 5,601,561,107$ \\
Facilities & 5 & $£ 4,563,279,000$ \\
Building materials & 2 & $£ 3,125,800,000$ \\
Energy & 1 & $£ 2,000,000,000$ \\
Utility Company & 1 & $£ 1,808,000,000$ \\
Energy retailer & 1 & $£ 1,206,115,000$ \\
Post & 4 & $£ 1,189,477,000$ \\
Marketing & 5 & $£ 940,428,364$ \\
Furniture & 7 & $£ 440,090,341$ \\
Security & 6 & $£ 304,504,424$ \\
Foster agency & 1 & $£ 40,525,321$ \\
Dormant & 1 & $£ 2,536,000$ \\
Retail & 1 & $£ 2,400,000$ \\
Storage & 1 & $£ 1,600,000$ \\
Health & 1 & $\mathrm{~N} / \mathrm{A}$ \\
Total & & $£ 159,720,966,110$ \\
\hline
\end{tabular}

\section{Appendix 2: Example content evaluators (adapted from ETI, 2019)}

Key content descriptors (Section 6 training)

Level 1:

Overview of existing training policies and procedures relevant to modern slavery

Training needs assessment with list of particular groups (including suppliers) that should receive modern slavery training/capacity building

Plan (with specific time-bound objectives) to develop and roll out appropriate modern slavery training/capacity building initiatives and evaluation system
Key content descriptors (Section 6 training)

Level 2:

As Level 1, plus:

Evidence that modern slavery modules are included in existing training programmes and/or that a specific modern slavery training and capacity building programme has been developed, with understanding and skills identified and assessed

Level 3:

As Level 2, plus:

Measures of training outcomes (e.g. changes in awareness) and capacity building outcomes (e.g. changes in number/quality of supplier due diligence plans)

Evidence of ongoing review and revision of training and capacity building

Evidence that training and capacity building programme has been developed in consultation with external stakeholders

\section{Relevant information to include}

Which groups have been provided with training (e.g. buying teams, senior management, specific contractors, suppliers and their workers) and which groups have not

Who provides training and capacity building activities

What the objectives and outcomes are for each activity mentioned

How training and capacity building take place (e.g. workshops, webinars, videos, manuals, eLearning, etc.)

Evidence and detail of stakeholder collaboration in developing and implementing training and capacity building programmes

Information on the frequency and regularity of training

External training that your employees, or your suppliers' employees, have participated in (such as by ETI)

Acknowledgements The researchers would like thank Dr. Owain Johnstone of the Ethical Trading Initiative (ETI) for his guidance in ensuring that the modern slavery assessment framework was applied consistently and in accordance with design intentions.

Funding No funding was received for conducting this study.

\section{Declarations}

Conflict of interest The authors have no relevant financial or non-financial interests to disclose.

Open Access This article is licensed under a Creative Commons Attribution 4.0 International License, which permits use, sharing, adaptation, distribution and reproduction in any medium or format, as long as you give appropriate credit to the original author(s) and the source, provide a link to the Creative Commons licence, and indicate if changes were made. The images or other third party material in this article are included in the article's Creative Commons licence, unless indicated otherwise in a credit line to the material. If material is not included in the article's Creative Commons licence and your intended use is not permitted by statutory regulation or exceeds the permitted use, you will need to obtain permission directly from the copyright holder. To view a copy of this licence, visit http://creativecommons.org/licenses/by/4.0/. 


\section{References}

Armstrong, D., Gosling, A., Weinman, J., et al. (1997). The place of inter-rater reliability in qualitative research: An empirical study. Sociology, 31(3), 597-606.

AuGov. (2018). Commonwealth Modern Slavery Act 2018: Guidance for Reporting Entities. Available at: https://modernslaveryregister. gov.au/resources/MSA_-_Official_Guidance_.pdf. Accessed 14 June 2021.

Barna, A. G. (2017). The early eight and the future of consumer legal activism to fight modern-day slavery in corporate supply chains. William \& Mary Law Review, 59, 1449.

Bebbington, J., Kirk, E. A., \& Larrinaga, C. (2012). The production of normativity: A comparison of reporting regimes in Spain and the UK. Accounting, Organizations and Society, 37(2), 78-94.

Benstead, A. V., Hendry, L. C., \& Stevenson, M. (2018). Horizontal collaboration in response to modern slavery legislation: An action research project. International Journal of Operations \& Production Management, 38(12), 2286-2312.

Benstead, A. V., Hendry, L. C., \& Stevenson, M. (2021). Detecting and remediating modern slavery in supply chains: A targeted audit approach. Production Planning \& Control, 32(13), 1136-1157.

BHRRC. (2019). FTSE 100 \& the UK Modern Slavery Act. Available at: https://www.modernslaveryregistry.org/pages/FTSE_100_ reports. Accessed 16 Oct 2020

Birkey, R. N., Guidry, R. P., Islam, M. A., et al. (2018). Mandated social disclosure: An analysis of the response to the California Transparency in Supply Chains Act of 2010. Journal of Business Ethics, 152(3), 827-841.

Charmaz, K. (2014). Constructing grounded theory. Sage.

Chauvey, J.-N., Giordano-Spring, S., Cho, C. H., et al. (2015). The normativity and legitimacy of CSR disclosure: Evidence from France. Journal of Business Ethics, 130(4), 789-803.

Chelli, M., Durocher, S., \& Fortin, A. (2018). Normativity in environmental reporting: A comparison of three regimes. Journal of Business Ethics, 149(2), 285-311.

Chen, J.-Y., \& Slotnick, S. A. (2015). Supply chain disclosure and ethical sourcing. International Journal of Production Economics, 161, 17-30.

Chen, S., Zhang, Q., \& Zhou, Y. P. (2019). Impact of supply chain transparency on sustainability under NGO scrutiny. Production and Operations Management, 28(12), 3002-3022.

Christ, K. L., Rao, K. K., \& Burritt, R. L. (2019). Accounting for modern slavery: an analysis of Australian listed company disclosures. Accounting, Auditing \& Accountability Journal, 32, 836.

Cole, R., \& Aitken, J. (2019). Selecting suppliers for socially sustainable supply chain management: Post-exchange supplier development activities as pre-selection requirements. Production Planning \& Control, 30(14), 1184-1202.

Cossart, S., Chaplier, J., \& De Lomenie, T. B. (2017). The French law on duty of care: A historic step towards making globalization work for all. Business and Human Rights Journal, 2(2), 317-323.

Crane, A. (2013). Modern slavery as a management practice: Exploring the conditions and capabilities for human exploitation. Academy of Management Review, 38(1), 49-69.

Crane, A., LeBaron, G., Allain, J., et al. (2019). Governance gaps in eradicating forced labor: From global to domestic supply chains. Regulation \& Governance, 13(1), 86-106.

Doorey, D. J. (2011). The transparent supply chain: From resistance to implementation at Nike and Levi-Strauss. Journal of Business Ethics, 103(4), 587-603.

ETI. (2019). Modern slavery statements evaluation framework. Available at: https://www.ethicaltrade.org/issues/modern-slavery/ modern-slavery-statements-evaluation-framework. Accessed 16 Oct 2020
Feasley, A. (2015). Deploying disclosure laws to eliminate forced labour: Supply chain transparency efforts of Brazil and the United States of America. Anti-Trafficking Review Special Issue: Forced Labour and Human Trafficking, 5, 30.

Field, F., Butler-Sloss, E., \& Miller, M, (2019), Independent Review of the Modern Slavery Act 2015: Final Report.

Flynn, A. (2020). Determinants of corporate compliance with modern slavery reporting. Supply Chain Management: An International Journal, 25(1), 1-16.

Flynn, A., \& Walker, H. (2021). Corporate responses to modern slavery risks: An institutional theory perspective. European Business Review, 33(2), 295-315.

Fudge, J. (2018). Modern slavery, unfree labour and the labour market: The social dynamics of legal characterization. Social \& Legal Studies, 27(4), 414-434.

Glaser, B. (1978). Theoretical sensitivity: Advances in the methodology of grounded theory. Sociology press Mill Valley.

Gold, S., \& Heikkurinen, P. (2018). Transparency fallacy. Accounting, Auditing \& Accountability Journal, 31(1), 318-337.

Gold, S., Trautrims, A., \& Trodd, Z. (2015). Modern slavery challenges to supply chain management. Supply Chain Management: An International Journal, 20(5), 485-494.

Government Commercial Function. (2019). Tackling modern slavery in Government supply chains: A guide for commercial \& procurement professionals. Government Commercial Function.

Grimm, J. H., Hofstetter, J. S., \& Sarkis, J. (2016). Exploring subsuppliers' compliance with corporate sustainability standards. Journal of Cleaner Production, 112, 1971-1984.

Grimm, J. H., Hofstetter, J. S., \& Sarkis, J. (2018). Interrelationships amongst factors for sub-supplier corporate sustainability standards compliance: An exploratory field study. Journal of Cleaner Production, 203, 240-259.

Gutierrez, J. A. (2017). Less than transparent: How California's effort to shine light on modern slavery may ultimately keep consumers in the dark. Loyola Journal of Public Interest Law, 19, 57.

Harris, K. D. (2015). The California transparency in supply chains act: A resource guide. Available at: https://oag.ca.gov/sites/all/files/ agweb/pdfs/sb657/resource-guide.pdf. Accessed 14 June 2021

Hess, D. (2019). The transparency trap: Non-financial disclosure and the responsibility of business to respect human rights. American Business Law Journal, 56(1), 5-53.

HMG, (2018). Transparency in supply chains: a practical guide. Available at: https://www.gov.uk/government/publications/transparen cy-in-supply-chains-a-practical-guide. Accessed 20 May 2020.

HMG, (2019a). Government leads the way in tackling modern slavery in public procurement. Available at: https://www.gov.uk/gover nment/news/government-leads-the-way-in-tackling-modern-slave ry-in-public-procurement. Accessed 24 Oct 2020.

HMG. (2019b). UK Government response to the independent review of the Modern Slavery Act 2015. Available at: https://www.gov. uk/government/publications/government-response-to-the-indep endent-review-of-the-modernslavery-act. Accessed 12 Apr 2021.

HMG. (2020). UK government modern slavery statement. Available at: https://www.gov.uk/government/publications/uk-governmentmodern-slavery-statement. Accessed 20 May2020.

Huq, F. A., \& Stevenson, M. (2020). Implementing socially sustainable practices in challenging institutional contexts: Building theory from seven developing country supplier cases. Journal of Business Ethics, 161(2), 415-442.

ILO. (2019). Forced labour, modern slavery and human trafficking. Available at: https://www.ilo.org/global/topics/forced-labour/ lang--en/index.htm. Accessed 12 Apr 2021.

Koekkoek, M., Marx, A., \& Wouters, J. (2017). Monitoring forced labour and slavery in global supply chains: The case of the California Act on transparency in supply chains. Global Policy, 8(4), 522-529. 
LeBaron, G., \& Rühmkorf, A. (2017). Steering CSR through home state regulation: A comparison of the impact of the UK bribery act and modern slavery act on global supply chain governance. Global Policy, 8, 15-28.

LeBaron, G., \& Rühmkorf, A. (2019). The domestic politics of corporate accountability legislation: Struggles over the 2015 UK Modern Slavery Act. Socio-Economic Review, 17(3), 709-743.

Marshall, D., McCarthy, L., McGrath, P., et al. (2016). What's your strategy for supply chain disclosure? MIT Sloan Management Review, 57(2), 37-45.

Martin-Ortega, O. (2018). Public procurement as a tool for the protection and promotion of human rights: A study of collaboration, due diligence and leverage in the electronics industry. Business and Human Rights Journal, 3(1), 75-95.

Meehan, J., \& Pinnington, B. D. (2021). Modern slavery in supply chains: Insights through strategic ambiguity. International Journal of Operations \& Production Management, 41(2), 77-101.

Michelon, G., Pilonato, S., \& Ricceri, F. (2015). CSR reporting practices and the quality of disclosure: An empirical analysis. Critical Perspectives on Accounting, 33, 59-78.

Monciardini, D., Bernaz, N., \& Andhov, A. (2021). The organizational dynamics of compliance with the UK Modern Slavery Act in the food and tobacco sector. Business \& Society, 60(2), 288-340.

New, S. (2010). The transparent supply chain. Harvard Business Review, 88, 1-5.

New, S. J. (2015). Modern slavery and the supply chain: The limits of corporate social responsibility? Supply Chain Management: An International Journal, 20(6), 697-707.

New, S. J., et al. (2020). Modern slavery and supply chain transparency. In T. Y. Choi, J. J. Li, \& D. S. Rogers (Eds.), The Oxford handbook of supply chain management. Oxford University Press.

Rogerson, M., Crane, A., Soundararajan, V., et al. (2020). Organisational responses to mandatory modern slavery disclosure legislation: A failure of experimentalist governance? Accounting, Auditing \& Accountability Journal, 33(7), 1505-1534.

Saldana, J. (2016). the coding manual for qualitative researchers. Sage Publications Ltd.
Soundararajan, V., \& Brammer, S. (2018). Developing country subsupplier responses to social sustainability requirements of intermediaries: Exploring the influence of framing on fairness perceptions and reciprocity. Journal of Operations Management, 58, $42-58$.

Stevenson, M., \& Cole, R. (2018). Modern slavery in supply chains: A secondary data analysis of detection, remediation and disclosure. Supply Chain Management: An International Journal, 12(3), 81-99.

Swift, C., Guide, V. D. R., Jr., \& Muthulingam, S. (2019). Does supply chain visibility affect operating performance? Evidence from conflict minerals disclosures. Journal of Operations Management, 65(5), 406-429.

Voss, H., Davis, M., Sumner, M., et al. (2019). International supply chains: Compliance and engagement with the Modern Slavery Act. Journal of the British Academy, 7(s1), 61-76.

WFF. (2018). Global Slavery Index: Regional Analysis. Asia and the Pacific. Available at: https://www.globalslaveryindex.org/2018/ findings/regional-analysis/asia-and-the-pacific/. Accessed $12 \mathrm{Apr}$ 2021.

Wilhelm, M., Blome, C., Bhakoo, V., et al. (2016a). Sustainability in multi-tier supply chains: Understanding the double agency role of the first-tier supplier. Journal of Operations Management, 41, 42-60.

Wilhelm, M., Blome, C., Wieck, E., et al. (2016b). Implementing sustainability in multi-tier supply chains: Strategies and contingencies in managing sub-suppliers. International Journal of Production Economics, 182, 196-212.

Publisher's Note Springer Nature remains neutral with regard to jurisdictional claims in published maps and institutional affiliations. 